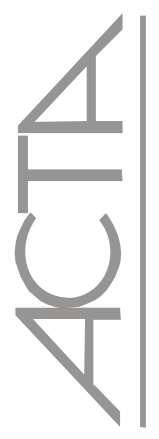

\title{
Interdisciplinaridade: uma contextualização
}

\author{
Interdisciplinarity: a contextualization
}

Interdisciplinaridad: una contextualización

\section{Maria Lúcia Borges Gattás ${ }^{1}$, Antonia Regina Ferreira Furegato ${ }^{2}$}

\section{RESUMO}

Este texto apresenta as bases teóricas para abordagem empírica sobre a interdisciplinaridade. Diversos aspectos foram considerados nesta reflexão, apontando as dificuldades de compreensão do tema tanto do ponto de vista teórico e, de sua aplicação como das divergências sobre o tema.

Descritores: Conhecimento; Educação; Filosofia; Saúde; Enfermagem

\footnotetext{
ABSTRACT

This paper discusses the theoretical bases for an empirical approach to interdisciplinary work. Various aspects have been considered in this reflection, such as, difficulties to understand the theme in terms of theoretical underpinning, practice application of the theme, and scholars' disagreements about the theme.

Keywords: Knowledge; Education ; Philosophy; Health; Nursing

\section{RESUMEN}

Este texto presenta las bases teóricas para el abordaje empírico sobre la interdisciplinaridad. En esta reflexión fueron considerados diversos aspectos, apuntando las dificultades para la comprensión del tema, tanto desde el punto de vista teórico y de su aplicación , como de las divergencias existentes sobre el tema.

Descriptores: Conhecimiento; Educación; Filosofía; Salud; Enfermería
}

\footnotetext{
${ }^{1}$ Doutora em Enfermagem Psiquiatrica. Docente da Universidade de Uberaba - UNIUBE - Uberaba (MG), Brasil.

${ }^{2}$ Professora Titular do Departamento Enfermagem Psiquiátrica e Ciências Humanas da escola de enfermagem de Ribeirão Preto da Universidade de São Paulo - USP - São Paulo (SP), Brasil.
} 


\section{INTRODUÇÃO}

De um extenso levantamento bibliográfico que deu suporte a uma tese sobre interdisciplinaridade ${ }^{(1)}$ merecem destaque os principais autores que se dedicam ao estudo deste tema, tanto do ponto de vista teórico como de sua aplicação.

$\mathrm{O}$ assunto é instigante não tendo, entretanto, um sentido unívoco e nem uma "teoria" da interdisciplinaridade. Não há consenso sobre seus conceitos e a tentativa de explicitação vem acompanhada de riqueza de vertentes, na abordagem da questão. É um tema mais teorizado do que propriamente praticado, tendo inclusive críticas quanto a sua aplicabilidade.

\section{DAS FALAS DE GUSDORF E JAPIASSU}

O precursor dos estudos sobre a interdisciplinaridade na França ${ }^{(2)}$ é um ferrenho crítico da especialização. Ao prefaciar o livro "Interdisciplinaridade e Patologia do Saber" discorre de maneira sensível sobre a evolução do conhecimento, desde os primórdios, quando as relações do homem com o mundo se processavam de maneira orgânica, em completa comunhão com a natureza. Esse saber, em tempos remotos, era um saber de totalidade, um saber que permitia o desabrochar da personalidade integral: enkuklio. Paidéia era o ideal da cultura grega. Paidéia designava, em sua origem, o conjunto de estudos circulares, completo e perfeito, na medida em que recobria completamente o horizonte do conhecimento. Um programa de estudos dessa natureza reunia disciplinas que não eram herméticas e indiferentes umas às outras. Pelo contrário, articulavam-se entre si, complementavamse, formando um todo harmônico e unitário.

A exigência interdisciplinar impõe às especialidades que transcendam suas próprias áreas, tomando consciência de seus limites e acolhendo as contribuições das outras disciplinas. Uma epistemologia de complementaridade, de convergência deve substituir a dissociação tão freqüente na modernidade ${ }^{(2)}$.

O desenvolvimento técnico-científico decorrente da crescente e rápida especialização tem conduzido à pulverização, ao esmigalhamento do conhecimento e à divisão dos saberes em diversas disciplinas ou ramos do saber, dando origem às especialidades e subespecialidades $^{(2)}$. Os óbices à interdisciplinaridade são de ordem epistemológica, institucionais, psico-sociológicas e culturais. O especialista não visualiza o conjunto porque está cativo dos detalhes. A disciplina, uma vez emancipada, consolida-se por via administrativa, tende a centrar-se sobre si mesma e não se comunica com outros espaços mentais e intelectuais. Os espaços intelectuais compartimentados conduzem à formação de sistemas feudais que controlam as iniciativas de ensino e de investigação(2).

O conhecimento interdisciplinar, por muito tempo, condenado ao ostracismo em decorrência dos preconceitos positivistas, tem um campo vasto e complexo. Assim, um projeto, sob esta perspectiva, enfrenta várias dificuldades, não só do ponto de vista conceitual como também metodológico e ideológico ${ }^{(3)}$. Focalizar a interdisciplinaridade como uma exigência interna das ciências humanas para melhor compreensão da realidade pode ser traduzida por um diálogo que propicia o desvelamento global da existência humana.

A interdisciplinaridade coloca-se como desestímulo à multiplicação desordenada de especialidades, buscando as relações de interdependências e de conexões recíprocas entre as disciplinas; caracteriza-se pela intensidade das trocas entre especialistas e pelo grau de integração real das disciplinas, no interior de um mesmo projeto de pesquisa. $O$ processo interativo se faz pela comparação dos resultados obtidos em uma disciplina com os resultados fornecidos por outra disciplina, pelo confronto dos pontos de vista ou enfoques diferentes, podendo essa interação ir da simples comunicação das idéias à integração mútua. Nesse processo, o papel específico da atividade interdisciplinar consiste em lançar pontes para religar as fronteiras das disciplinas onde cada uma delas sai enriquecida e, ao mesmo tempo, com conhecimento mais "inteiro" e "harmonioso" do fenômeno humano ${ }^{(4)}$.

\section{DOS ENTENDIMENTOS DE FAZENDA, SEVERINO, POMBO E LÜCK}

Focalizando novamente este ponto observa-se que o vocábulo interdisciplinaridade ainda não tem significado bem definido, estável. A interdisciplinaridade implica relação de reciprocidade, de mutualidade, de substituição da concepção fragmentária por uma concepção unitária do ser humano, ou seja, um movimento de renovação frente aos problemas do ensino e da pesquisa ${ }^{(5)}$.

A interdisciplinaridade é um processo que precisa ser vivido, reclama atitude interdisciplinar que se caracteriza por ousadia de busca, de pesquisa; transforma a insegurança num exercício de pensar, de construir; respeita o modo de ser de cada um e o caminho que cada um empreende na busca de autonomia; exige a elaboração de um projeto inicial que seja claro e coerente para que as pessoas sintam o desejo de fazer parte dele; pode ser aprendida e ensinada o que pressupõe o fato de perceberse interdisciplinar ${ }^{(5-6)}$.

A interdisciplinaridade é uma tarefa inacabada porque não se consegue definir o que vem a ser vinculação, reciprocidade, interação, comunidade de sentido ou de complementaridade entre as várias disciplinas ${ }^{(7)}$.

Essa incompreensão vem da falta de experiência vivida, explicitada e sua prática concreta é ainda um 
processo incipiente na elaboração do saber, na atividade de ensino e de pesquisa e na ação social. A interdisciplinaridade é algo pressentido, desejado e buscado, mas ainda não atingido.

Uma visão interdisciplinar unificada e convergente implica estar presente tanto no campo da teoria como da prática (de intervenção social, pedagógica ou de pesquisa). O homem é uma unidade que só pode ser apreendida numa abordagem sintetizadora e nunca pela acumulação de visões parcelares. Pelo processo de decomposição, análise e recomposição das partes essa soma nunca chegará à totalidade ${ }^{(7)}$.

No âmbito dos esforços, com vistas ao conhecimento da realidade humana, deve-se praticar uma dialética e os conhecimentos advindos dessa dialética irão fornecer os elementos para a construção do sentido de totalidade. Isso desperta para uma série de conseqüências que dizem respeito à interdisciplinaridade, relativas à atuação dos educadores nos vários campos do saber: as fronteiras entre as várias áreas e ciências relativas ao homem ficam radicalmente diluídas ${ }^{(7)}$.

No estudo "A Interdisciplinaridade: reflexão e experiência"(8), a interdisciplinaridade surge na educação não como uma nova proposta pedagógica, mas como uma "aspiração" emergente entre os próprios professores. A interdisciplinaridade apresenta-se como o exercício de alguma coisa que se faz entre um objeto voluntarista (no qual acreditamos e temos vontade de fazer) e, ao mesmo tempo é alguma coisa que vai acontecendo, quer queiramos ou não ${ }^{(8)}$. Estabelece-se uma intimidade com essa palavra, que não é só uma, desdobra-se em pelo menos quatro: pluridisciplinaridade, multidisciplinaridade, interdisciplinaridade e transdisciplinaridade. Esta diversidade conceitual dificulta o estabelecimento de limites e fronteiras que não são simples para quem as usa, para quem as estuda ou para quem quer definições.

A incapacidade de se compreender o significado dessas palavras reside na maneira como fomos formados, treinados, como funcionamos e como elas fazem parte de nossa atitude. Para tornar essas palavras mais compreensivas é preciso encaminhá-las em direção a outra palavra concorrente: integração. Entende-se muito bem quando se fala em integração dos saberes, das disciplinas, de ações, de mundialização e de globalização( ${ }^{(8)}$.

Estudiosos do tema têm procurado estabelecer acordos terminológicos e conceituais, relativos à interdisciplinaridade. Essas palavras estão ligadas entre si pelo radical disciplina. Para os possíveis consensos, procura-se estabelecer distinções relativamente a uma rede de conceitos afins, evidenciando-se oposições e diferenças. O conceito de multidisciplinaridade aparece, com freqüência, como sinônimo ou equivalente ao de pluridisciplinaridade. A multidisciplinaridade seria a “justaposição" de disciplinas diversas, às vezes sem relação aparente entre elas e a pluridisciplinaridade seria a "justaposição" de disciplinas mais ou menos próximas nos seus campos de conhecimentos ${ }^{(8)}$. Nessa relação triádica, o conceito de interdisciplinaridade ocupa uma posição intermediária em relação às outras. A interdisciplinaridade é pensada como algo que se deve entender como mais do que a pluridisciplinaridade e menos do que a transdisciplinaridade.

A tese central defendida por um desses autores ${ }^{(8)}$ é de que os conceitos de pluridisciplinaridade, interdisciplinaridade e transdisciplinaridade, enquanto caracterizadores de diversificadas práticas de ensino, devem ser entendidos como momentos de um mesmo contínuo: o processo progressivo de integração disciplinar (ou ensino integrado), isto é, formas de ensino que estabeleçam alguma articulação entre duas ou mais disciplinas.

A pluridisciplinaridade seria o pólo mínimo da integração disciplinar, a transdisciplinaridade seria o pólo máximo e a interdisciplinaridade aglutinaria o conjunto das múltiplas variações possíveis entre os dois extremos ${ }^{(8)}$.

Quando uma experiência de ensino integrado, ultrapassa esses mínimos, estaríamos vivenciando uma experiência interdisciplinar.

Interdisciplinaridade pode ser entendida como qualquer forma de combinação entre duas ou mais disciplinas objetivando-se a compreensão de um objeto a partir da confluência de pontos de vista diferentes cujo objetivo final seria a elaboração de síntese relativa ao objeto comum; implica alguma reorganização do processo ensino/ aprendizagem e supõe trabalho contínuo de cooperação entre os professores envolvidos.

A interdisciplinaridade, além do componente cognitivo que a constituí, também é pensada em termos de atitude. Esse padrão revela-se através de uma idéia, uma prática, um projeto que tenha como base a autêntica vontade de colaboração, cooperação, diálogo e abertura ao outro. Paralelamente, é pensável em termos de poder. A interdisciplinaridade não anula as formas de poder que todo o saber comporta, mas exige a disponibilidade para partilhar o poder, isto é, partilhar um saber e um poder que se tem consciência de não ser proprietário. Trata-se de não ocultar o seu próprio saber/poder, mas, ao contrário, torná-lo discursivo e acessível à compreensão de outros ${ }^{(9)}$.

A construção interdisciplinar reclama o envolvimento de educadores na busca de soluções para os problemas relacionados ao ensino e à pesquisa. O objetivo da interdisciplinaridade é o de promover a superação da visão parcelar de mundo e facilitar a compreensão da complexidade da realidade e, desse modo, resgatar a centralidade do homem, compreendendo-o como ser determinante e determinado. No contexto do ensino, o conceito de interdisciplinaridade é um processo que 
envolve a integração e o engajamento de educadores, num trabalho conjunto, de interação das disciplinas do currículo escolar entre si e com a realidade. Superando a fragmentação, o ensino, objetiva a formação integral dos alunos, para exercem criticamente sua profissão, sendo capazes de enfrentar os problemas complexos e globais da realidade atual ${ }^{(10)}$.

\section{AS CONTRIBUIÇÕES DE JANTSCH \& BIANCHETTI, ETGES FRIGOTTO E ON}

Os organizadores do livro "Interdisciplinaridade: para além da filosofia do sujeito"(11), escrito por vários autores e outros críticos da visão interdisciplinar ${ }^{(11-13)}$ consideram que o processo de fragmentação do conhecimento e do trabalho se impôs e fazem críticas à interdisciplinaridade. Essas críticas são baseadas no referencial teórico do materialismo histórico e dialético, levando à desconstrução dos aspectos relativos ao sujeito, ao método e à ausência de historicidade.

A crítica está centrada na idéia de "sujeito coletivo", aquele que emerge da equipe de trabalho. Os autores encaminham a discussão no sentido da concepção hegemônica a-histórica do objeto filosófico-científico. Para eles, a filosofia do sujeito é a base e a expressão maior da concepção a-histórica, relativa à interdisciplinaridade. Não negam as possíveis contribuições da filosofia do sujeito na produção historicamente acumulada do conhecimento. No entanto, seja na circunstância idealista ou em outra que incorra em a-historicidade não vêem substrato suficiente para configurar a construção histórica do objeto "interdisciplinaridade". Assinalam que a construção histórica de um objeto implica sua construção e compreensão, aceitando, desse modo, a tensão entre o sujeito pensante e as condições objetivas para o pensamento.

Não concordam com vários pressupostos relativos à interdisciplinaridade tais como: que a especialização seja um mal que compromete a ciência e que deve ser extirpado; que a interdisciplinaridade só é fecunda no trabalho em equipe e pode ser vivenciada em qualquer espaço de atuação, surgindo a idéia da paninterdisciplinaridade; que o sujeito coletivo seja capaz de superar dificuldades relativas à fragmentação do conhecimento; que a produção do conhecimento esteja superada com o trabalho em parceria. Entendem que estes pressupostos estão baseados no campo das idéias, não levando em consideração os diferentes momentos históricos, seu processo e as diferentes formas de criação do conhecimento, e a idéia de pan-interdisciplinaridade na metodologia como uma solução para todos os males da fragmentação do conhecimento ${ }^{(11)}$.

A interdisciplinaridade proposta não se funda no plano metafísico, mas no trabalho dos cientistas, partem da lógica que provém do trabalho e da ciência como produção de novos mundos, adequados ao sujeito. Tal como o sujeito e a inteligência de onde ela emana, a ciência constitui a totalidade fechada e completa, em si mesma, e só tem existência pela exteriorização que se dá através da linguagem. A linguagem científica, por ser adequada aos novos objetos construídos, é específica, exata e esotérica. É específica, por excluir tudo aquilo que não se refere ao objeto do estudo; exata por romper com o mundo das representações, da intuição; e, esotérica por essas determinações não estarem imediatamente acessíveis ao senso comum, nem mesmo ao próprio cientista ${ }^{(12)}$.

O conhecimento produzido pela ciência precisa retornar ao sujeito para promover a unidade. A interiorização do exterior é um ato interdisciplinar. A interdisciplinaridade seria uma ação de transposição do produzido e conhecido para as estruturas internas do indivíduo sem reduzir as ciências a um denominador comum $^{(12)}$.

A interdisciplinaridade exige refazer, reconstruir e reestruturar a instituição universitária o que exige esforço de superação, desburocratização de departamentos e realização de novos projetos ${ }^{(11)}$.

A discussão da interdisciplinaridade na educação está focada no âmbito das ciências sociais ${ }^{(13)}$. O caráter do trabalho interdisciplinar na produção e socialização do conhecimento traz no seu bojo a necessidade de conhecer esse homem, sua forma de produzir-se enquanto ser social e enquanto sujeito e objeto do conhecimento social.

A interdisciplinaridade baseia-se no caráter dialético da realidade social e na unicidade e diversidade dessa realidade social e na intersubjetividade que envolve a sua apreensão ${ }^{(13)}$.

A interdisciplinaridade não é um método de investigação, técnica didática, instrumento utilitário, princípio de homogeneização, ou mesmo modelo metodológico capaz de produzir conhecimentos amplos, unitários ou mesmo universalizantes ${ }^{(14)}$. É uma postura profissional que permite transitar o "espaço da diferença" com sentido de busca e de desvelamento das diferentes formas de se abordar a realidade. Nenhuma profissão e conhecimentos são absolutos e a interdisciplinaridade é um princípio constituinte da diferença e da criação ${ }^{(12)}$. É uma alternativa para transpor as fronteiras das profissões, sem perda de autonomia, de oportunidades de conhecer outras formas de ação, de superar idiossincrasias, de deixar de falar só com seus pares e de aprender a conviver ${ }^{(14)}$.

\section{DISCUSSÃO}

O estudo da interdisciplinaridade é ainda incipiente, não oferecendo segurança teórica e metodológica para àqueles que se sentem atraídos para desenvolver um 
trabalho dessa envergadura. Há unanimidade quanto à falta de compreensão do tema, de abordagem difícil de ser entendida e aplicada, envolvendo variáveis que fogem ao controle porque dependentes de construção de trabalho coletivo e, nessa situação, ela se faz não só envolvendo os saberes, mas, também, intersubjetividades, isto é, o processo no nível das relações interpessoais.

Divergências e críticas apresentadas por alguns autores destacam a forma como a interdisciplinaridade é descrita. Para eles, a interdisciplinaridade não se funda no plano metafísico, na vontade do sujeito, mas, como produto da ciência, cuja integração do conhecimento se processa nas estruturas internas do indivíduo, ao conhecer seu objeto de estudo. A interdisciplinaridade seria uma ação de transposição do produzido e conhecido para as estruturas internas do indivíduo e não como um ato voluntarioso associado à construção de um trabalho coletivo.

Aspecto comum a todos foi perceber a interdisciplinaridade como atitude, postura profissional que envolve capacidade de cooperação, respeito à diversidade, abertura para o outro, vontade de colaboração, diálogo, humildade, ousadia.

Essas disposições não são realidades excludentes, mas complementares no estudo da interdisciplinaridade. Alguns autores são mais vibrantes em suas colocações passando a impressão que a realização do processo se dá pela intersecção de fatores favoráveis, dependentes da vontade de vivenciar uma maneira inovadora de lidar com o conhecimento e de sua aplicação no mundo do vivido, numa relação não hierárquica, numa construção de trabalho em conjunto com suas redes de conexões; há outros mais comedidos, ligados a um tronco arborescente de onde emana a direção a ser seguida, e, cujas relações, são hierárquicas e previsíveis.

Acreditamos que tudo tem a ver com a forma como fomos acostumados a lidar e a transmitir o conhecimento e que o aspecto fundamental do trabalho interdisciplinar, de concepção teórica ou prática, seja a troca de conhecimentos que se estabelece no interior das interações, enriquecendo os conhecimentos, ampliando os campos de visão dos profissionais envolvidos.

\section{CONCLUSÃO}

A universidade, enquanto campo de ensino deve estar preparada para a interdisciplinaridade. É preciso promover essa experiência, facilitando as novas configurações e apresentações, criando as circunstâncias e os mecanismos que favoreçam a compreensão dos fenômenos que nela ocorrem.

Essa disposição faz com que a universidade encontre formas de articulações diferentes das convencionais: divisões em faculdades, departamentos e disciplinas. No futuro, talvez venham a se constituir em cursos interdisciplinares, flexíveis, onde os alunos encontrem seu próprio caminho no interior das carreiras que lhes são oferecidas.

O assunto é atual, instigante, pouco conhecido na prática e requer reflexão profunda. A adesão a um projeto interdisciplinar carece de transformações, desconstrução e reconstrução do que é apresentado tradicionalmente. Nisso está implícito o processo de aprender a aprender e o de aprender a conviver. Não deixa de ser um desafio para todos aqueles que se sentem atraídos pela sua prática. Respeito, abertura para o outro, vontade de colaboração, cooperação, tolerância, diálogo, humildade e ousadia são aspectos inerentes a esse processo.

A interdisciplinaridade é uma questão de atitude.

\section{REFERÊNCIAS}

1. Gattás MLB. Interdisciplinaridade em cursos de graduação na área da saúde da Universidade de Uberaba-UNIUBE [tese]. Ribeirão Preto: Escola de Enfermagem de Ribeirão Preto da Universidade de São Paulo; 2005.

2. Gusdorf G. Prefácio In: Japiassu H. Interdisciplinaridade e patologia do saber. Rio de Janeiro: Imago Editora; 1976.

3. Gusdorf G. Conhecimento interdisciplinar. In: Guimarães HM, Pombo O, Levy T. organizadores. Antologia I. Lisboa(PO): Mathesis; 1990.

4. Japiassu H. Interdisciplinaridade e patologia do saber. Rio de Janeiro: Imago Editora; 1976.

5. Fazenda ICA. Interdisciplinaridade: um projeto em parceria. São Paulo: Edições Loyola; 1999.

6. Fazenda ICA. Interdisciplinaridade: história, teoria e pesquisa. São Paulo: Papirus; 2001.

7. Severino JA. S. Subsídios para uma reflexão sobre novos caminhos da interdisciplinaridade. In: Severino AJ, Sá JM, organizadores. Serviço social e interdisciplinaridade: dos fundamentos filosóficos à prática interdisciplinar no ensino, pesquisa e extensão. São Paulo: Cortez; 2000.

8. Guimarães HM, Pombo O, Levy T, organizadores. A interdisciplinaridade: reflexão e experiência. Lisboa: Texto; 1994.

9. Pombo O. Interdisciplinaridade: ambições e limites. Lisboa: Relógio d'Água; 2004.

10. Lück H. Pedagogia interdisciplinar: fundamentos teóricometodológicos. Petrópolis; (RJ): Vozes; 2000.

11. Jantsch AP, Bianchetti L, organizadores. Interdisciplinaridade: para além da filosofia do sujeito. Petrópolis; (RJ): Vozes; 2000.

12. Etges NJ. Ciência, interdisciplinaridade e educação. In: Jantsch, Bianchetti L, organizadores. Interdisciplinaridade: para além da filosofia do sujeito. Petrópolis; (RJ): Vozes; 2000.

13. Frigotto G. A interdisciplinaridade como necessidade e como problema nas ciências sociais. Educ Realidade. 1993; 18(2): 63-72.

14. On ML. O Serviço Social e a perspectiva interdisciplinar. In: Martinelli ML, On ML, Muchail ST, organizadores. O Uno e o múltiplo nas relações entre as áreas do saber. São Paulo: Cortez; 1998. 